\title{
FutureJournal
}

\section{Data gathering for actor analyses: A research note on the collection and aggregation of individual respondent data for MACTOR}

\section{Gareth H Rees}

PhD Student in Health Workforce Forecasting at the University of Otago, New Zealand gareth.rees@postgrad.otago.ac.nz

\section{Stephen MacDonell}

Professor in the Department of Information Science, Otago Business School, University of Otago, New Zealand

stephen.macdonell@otago.ac.nz

\section{ABSTRACT}

The future studies augmentation with data on actors and their interactions is suggested as a means to reduce uncertainty and to account for extreme or unexpected future outcomes due to the involvement of multiple actors and their competing perspectives and options. In the context of New Zealand's health workforce forecasting environment, this research note presents a systematic method to gather and aggregate actor data developed for a recent foresight study. The method identifies the issues encountered and solutions developed when gathering data from time poor respondents representing diverse and sometimes oppositional actors, and for the coding and aggregation of these data for use in LIPSOR's actor analysis tool, MACTOR. Worked examples are provided to demonstrate the method's application with the software.

KEY-WORDS: Actor analysis. Actor data collection. MACTOR. Foresight. Health workforce forecasting. 


\section{INTRODUCTION}

Understanding the nuances of inherently complex health systems is of growing interest for governments and multi-lateral agencies. In particular, attention has been increasingly directed towards understanding how a system's actors act, react and interact with each other (de Savigny \& Adam, 2009). Such understanding is especially relevant for health workforce forecasting, where a range of sector actors interact across a health system. Of late, health workforce forecasting has been charged with being unreliable due to: its assumptions based in the existing service models and infrastructures (Gorman, 2015); its failure to accommodate interactions with the broader system; and its tendency to quantify problem size rather than highlight cost-effective solutions (National Health Workforce Planning and Research Collaboration, 2011). Health systems are also prone to dynamically conflicting political, social and institutional interests, further complicating forecasting efforts as the shifting balances of power may affect future events which are themselves difficult to deduce from the past (Bijl, 1992).

Whereas, futures studies tend to have little effect on public policy (Riedy, 2009) it has been suggested that by involving actors and their roles uncertainty can be reduced (Arcade, Godet, Meunier, \& Roubelat, 2009; Wright \& Cairns, 2011; Wright \& Goodwin, 2009). Actor analyses are therefore a useful tool when confronted by situations that are difficult to foresee and which involve multiple actors whose varying interests, perspectives, and options collide (Heger \& Rohrbeck, 2012). However, the actors' effective engagement to gather data can be hampered through participants' relative time poverty (Cairns, Wright, \& Fairbrother, 2016; Pincombe, Blunden, Pincombe, \& Dexter, 2013).

Actor analysis is defined as a "set of methods used to determine which actors are moreimportant within a sector" (Garrett, 1999: 289). It seeks to identify actors' strengths, weaknesses and stances on various issues, particularly points of agreement or disagreement, where an actor is "an institution, group, or individual that plays a major role within a particular sector" (Garrett, 1999: 289). A number of models and tools can be used to analyse the actors' dynamics within a system, drawing on matrix analysis, 
game theory or simulation (Bendahan, Camponovo, \& Pigneur, 2004). To undertake an actor analysis, a system's actors are identified, from which data are collected, examined and incorporated into forecasts. Adequate and accurate information can be difficult to obtain given political considerations and power influences, so experts who are familiar with the system and their actors may be invited to provide their opinions (Garrett, 1999).

What follows is a description of the efforts to address a methodological problem in the context of an ongoing foresight study. It focusses on the challenges faced when seeking to develop the highest quality input data for actor analysis via the MACTOR method, which is part of La Prospective's structured and methodical approach to scenario planning that uses a range of mathematical and computer based tools (Godet, Monti, Meunier, \& Roubelat, 2009). MACTOR is one of the few multi-actor issue analyses and is useful as it recognizes differences in power distribution (Heger \& Rohrbeck, 2012).

In particular, the aim in this note is to identify the methodological issues encountered and solutions developed, (i) when gathering data across an industry from time poor respondents representing diverse and sometimes oppositional actors, and (ii) when coding and aggregating these data to be used by the MACTOR software.

\section{THE MACTOR METHOD OF ACTOR ANALYSIS}

The French foresight tradition, La Prospective, arose as a result of what Godet refers to as classical forecasting's "repeated errors" (Godet, 1979 , p. 28), differing in viewpoint, variables and methods. A particular difference is regardingthe data; as part of La Prospective's futures methodology, qualitative subjective data in the form of the wishes and behaviours of the relevant actors are used (Godet, 1982). Indeed, Godet argues that "in order to identify the most probable results, it is necessary to fully understand the actors' projects and intentions, their methods of action on one another, coupled with the constraints imposed on them" (Godet, 1982: 296): for which the MACTOR method was later developed (Godet, 1991). 
The MACTOR method (Matrix of Alliances and Conflicts: Tactics, Objectives and Recommendations) is a six-step actor analysis sequence whose added value is obtained through calculations which reveal actor positions and power in relation to a number of strategic objectives (Arcade et al., 2009). The software is freely available for download through the LIPSOR website.

The MACTOR input data are formatted following the prescribed conventions of:

(i) descriptive qualitative data on the actor's plans, motivations, constraints, and means of action (compiled in the actor's strategy table),

(ii) the actors' positioning in relation to strategic objectives (compiled as numerical data into an actors by objectives table as to whether the actor is for $(+)$, neutral $(0)$ or against the objective (-) and the relative intensity or salience of the objective's importance to the actor using a scale of 0 (unimportant) to 4 (extremely important)), and

(iii) the influence of actors over each other (compiled numerical data as an actor by actor influence table measured on a scale ranging from 0 (no influence) to 4 (very high influence)).

The input data are stored as matrices, which the software later multiplies and whose products result in the various analysis outputs. These are in the form of charts and tables that represent the actors' relationships, positions and influences on the future development of the system.

The numerical data are derived through coding the responses to specific questions about an actor's preferences, relationships and how the actor will achieve his or her aims and objectives using the scales aforementioned. Comprehensive examples and instructions on how to collect, code and enter data and interpret the results can be found in Arcade et al. (2009), Godet (1991) and Godet, Bassaler, Monti, and Richou (2004). An example using a more recent version of the software can be found in Godet (2006).

The MACTOR method is versatile, in that it can be used for up to 20 actors and their associated objectives, while being simple and accessible 
(Godet et al., 2009). It, however, really possesses weaknesses. Firstly, the data gathered are, in many cases, confidential, thereby introducing access, verification and publishing problems (Godet et al., 2009). That said, due to the need for confidentiality, actors will more likely freely talk about their rivals and colleagues, which provides some cross checking and additional data assuming that the actors will be consistent on how they say they will act (Godet, 1991; Godet et al., 2009). Secondly, the ease with which results are produced can lead to result overload, chaotic diagrams and a never-ending task of digesting the copious information to develop a coherent picture: all of which points to the value of having high quality data at the outset (Arcade et al., 2009; Bendahan et al., 2004; Godet et al., 2009).

A limited number of MACTOR studies have been published in the peer reviewed literature. Out of these, 3 collected their data through workshops or seminars, 6 used experts, 2 used questionnaires, 1 used interviews, or combinations of these and 1 used solely literature based data. Chart 1 provides a brief summary of peer reviewed MACTOR studies.

\begin{tabular}{|c|c|c|c|c|}
\hline Author (Year) & Country & Industry & Study type & Data source \\
\hline Godet (1991) & France & Aviation & MACTOR study & Experts \\
\hline $\begin{array}{l}\text { Lafourcade and Chapuy } \\
\text { (2000) }\end{array}$ & France & Agriculture & $\begin{array}{l}\text { Foresight study } \\
\text { incorporating MACTOR }\end{array}$ & Workshop \\
\hline $\begin{array}{l}\text { Munteanu and Apetroae } \\
\text { (2007) }\end{array}$ & Romania & Education & MACTOR study & $\begin{array}{l}\text { Content } \\
\text { analysis }\end{array}$ \\
\hline $\begin{array}{l}\text { Ahmed, Saleh, Abdelkadir, } \\
\text { and Abdelrehim (2009) }\end{array}$ & Egypt & $\begin{array}{l}\text { Economic } \\
\text { Development }\end{array}$ & $\begin{array}{l}\text { Scenario study } \\
\text { incorporating MACTOR }\end{array}$ & $\begin{array}{l}\text { Workshops and } \\
\text { questionnaires }\end{array}$ \\
\hline Bettencourt (2010) & Azores & Government & $\begin{array}{l}\text { Prospective study } \\
\text { incorporating MACTOR }\end{array}$ & $\begin{array}{l}\text { Groups and } \\
\text { workshop }\end{array}$ \\
\hline $\begin{array}{l}\text { Vivanco-Aranda, Mojica, } \\
\text { and Martínez-Cordero } \\
\text { (2011) }\end{array}$ & Mexico & Aquaculture & $\begin{array}{l}\text { Foresight study, } \\
\text { incorporating MACTOR }\end{array}$ & Experts \\
\hline $\begin{array}{l}\text { Yamakawa, Cadillo, and } \\
\text { Tornero (2012) }\end{array}$ & Peru & Telecommunications & $\begin{array}{l}\text { Industry study } \\
\text { incorporating MACTOR }\end{array}$ & Experts \\
\hline $\begin{array}{l}\text { Heger and Rohrbeck } \\
(2012)\end{array}$ & Europe & Telecommunications & $\begin{array}{l}\text { Industry study } \\
\text { incorporating MACTOR }\end{array}$ & $\begin{array}{l}\text { Experts and } \\
\text { literature } \\
\text { analysis }\end{array}$ \\
\hline Lakner (2013) & Hungary & Education & MACTOR study & $\begin{array}{l}\text { Interviews and } \\
\text { experts }\end{array}$ \\
\hline $\begin{array}{l}\text { Lo, Wang, and Huang } \\
\text { (2013) }\end{array}$ & Taiwan & Energy & MACTOR study & $\begin{array}{l}\text { Experts and } \\
\text { questionnaires }\end{array}$ \\
\hline
\end{tabular}

Chart 1: Peer reviewed MACTOR studies

Source: Authors 


\section{METHODOLOGY}

\subsection{STUDY CONTEXT}

New Zealand's health sector operates within a dynamic policy context, which is mostly funded through state transfers (Gauld, 2005). This creates an environment where groups are in a state of conflict or rivalry, particularly the professions whose politics can inhibit proposed workforce solutions (Gorman \& Brooks, 2009). Tensions in health workforce planning can be found between actors such as: politicians, managers and clinicians and; management and health professionals and in situations. Underpinning such tensions are themes such as: authority, collegiality and accountability; business-as-usual; and flair, innovation and development (Health Workforce Advisory Committee, 2005). Such an environment of inter- and intraprofessional rivalry presents a challenging environment to improve workforce planning and, into which, propose suitable combinations of actions or solutions due to the sensitivities encountered when gathering sufficient, appropriate and trustworthy actor data (Garrett, 1999). Conventionally, data used in MACTOR are collected at prospective workshops or from experts, whose opinions are considered to be valid as their viewpoint is likely to be how the actor will proceed (Godet, 2000). However, other means for collecting data are required when there are few opportunities to collect data from actors in a group or where expert opinion is limited.

The method developed hereinspecifically canvasses a wide range of actors due to the professional divisions that mark the health sector (Glouberman \& Mintzberg, 2001; Gorman \& Brooks, 2009; Hinings, 2004). This enables a wider range of perspectives to be gathered across the professions and care philosophies that exist within the health system. The process was devised to overcome the challenge faced by these researchers. This was to develop a method that enables the data collection from a diverse range of time-poor informants across a range of actor groups and how to aggregate these data to fairly represent seven actors, while retaining data integrity and conforming to MACTOR's input requirements. 


\subsection{IDENTIFYING THE ACTORS}

The starting point for conducting an actor analysis is to build an initial list of potential (Varvasovszky \& Brugha, 2000) and relevant participants (Masini \& Medina Vasquez, 2000). As such, the selection of the actors was guided by recent New Zealand health workforce literature and government health planning documents. As two sub sectors are the subject of this study, reports and workforce planning documents specific to each field were also reviewed. From these, a list of respondents was compiled and contact information gathered. Chart 2 provides examples of the types of organizations identified for invitation into the study while Chart 3 provides details of the criteria to classify of these organizations in to seven actor groups.

\begin{tabular}{|l|l|}
\hline Health Sector & Education Sector \\
\hline Medical Regulatory Authorities & Polytechnics \\
\hline Professional Colleges & Universities \\
\hline Professional Registration Councils & Private Training Enterprises \\
\hline Medical Representative Organizations & Other tertiary providers \\
\hline Nursing Organizations & Government Funding Agencies \\
\hline Pharmacy provision and regulation & \\
\hline Other Specialist Professional colleges & \\
\hline District Health Boards (regional providers / Hospitals) & \\
\hline Government Funding and Regulatory Authorities & \\
\hline Primary Health Organizations (local community providers) & \\
\hline Allied and Community Health Professions & \\
\hline Private Hospitals & \\
\hline Health Charities & \\
\hline Community Representatives and Advocacy Groups & \\
\hline
\end{tabular}

\section{Chart 2 Types of New Zealand's health organizations}

Source. Authors.

\begin{tabular}{|c|c|}
\hline Actor & Classification \\
\hline Consumers* & $\begin{array}{l}\text { The people who use health services, who in this study are represented } \\
\text { by peak or sectorial bodies that have an advocacy role or welfare } \\
\text { interest in a population group or a sector which consume the health } \\
\text { system's services }\end{array}$ \\
\hline $\begin{array}{l}\text { Education } \\
\text { Providers }\end{array}$ & $\begin{array}{l}\text { The group of actors that provide the actual education and training } \\
\text { provision to the professionals and employee groups within the system }\end{array}$ \\
\hline Government & $\begin{array}{l}\text { The statutory bodies with roles prescribed by laws and that deliver } \\
\text { policy, purchasing, accreditation for institutions or provide for the } \\
\text { governing structure of the system }\end{array}$ \\
\hline Health Providers & $\begin{array}{l}\text { The group of actors that provide health care services to a range of } \\
\text { consumers }\end{array}$ \\
\hline
\end{tabular}




\begin{tabular}{|l|l|}
\hline \multicolumn{2}{|l|}{} \\
\hline Professional Body & $\begin{array}{l}\text { The group of actors that is responsible for the setting and monitoring } \\
\text { of standards for the different professions or specialties within the } \\
\text { system and that also play key roles in the vocational and continuing } \\
\text { education of those professionals. }\end{array}$ \\
\hline Regulatory Body & $\begin{array}{l}\text { The group of actors defined by the HPCA that sets standards and } \\
\text { manages the safety and of the health workforce on behalf of the } \\
\text { consumer }\end{array}$ \\
\hline $\begin{array}{l}\text { Representative } \\
\text { Body }\end{array}$ & $\begin{array}{l}\text { The group of actors which provide representation and advocacy for } \\
\text { employee and professional groups and who may deliver a range of } \\
\text { operational support and advice for the provision of their member's } \\
\text { professional services within the system }\end{array}$ \\
\hline
\end{tabular}

* The consumer actor group was selected from a range of broad-based, network or membership organizations which represent particular sections of the community such as Maori, disability, low socio-demographic and ethnicity, spanning both rural and urban geographic contexts.

\section{Chart 3 Classification of Actor Groups}

Source. Authors

\subsection{COLLECTING QUALITY DATA}

Interview planning and preparation are important for collecting quality data througha flow of questions, mapped out as a guide (Taylor, 2005). Lakner (2013) found that, due to MACTOR's data needs, his unstructured interviews did not easily reveal the data sought. To address this and to promote the engagement by time-poor respondents, semi structured interviews of forty-five minutes to one hour were used. After ascertaining the software's data needs (Godet et al., 2004), a data collection process and instrument were developed, to enable the data open discussion and to reduce recording subjectivity through pre-coded options. The data collection wasmanaged through a five-stage interview guide, where each stage contributed to a part of the MACTOR input data. Chart 4 relates the interview stages to the data gathered for MACTOR input.

Data quality is addressed through this process by careful interview design, the use of a specifically designed data recording form, and by using real-time data transcription techniques. The utilisation of a detailed interview guide improves data quality through the use of exact and repeatable openended questions, which allows for improved measurement and data credibility (Cicourel, 1964; MacKay \& McKiernan, 2010). 


\begin{tabular}{|l|l|l|}
\hline Interview Stage & Form of data & MACTOR data entry \\
\hline $\begin{array}{l}\text { 1. } \\
\text { Review the Actor } \\
\text { Information }\end{array}$ & $\begin{array}{l}\text { Confirm the actor's aims and } \\
\text { objectives, means and actions }\end{array}$ & $\begin{array}{l}\text { Table of Actors } \\
\text { Strategies }\end{array}$ \\
\hline 2. Actor's Purpose & $\begin{array}{l}\text { Objectives identified and the actor } \\
\text { stakes contextualised }\end{array}$ & $\begin{array}{l}\text { Actor } \times \text { Strategic } \\
\text { Issues table }\end{array}$ \\
\hline $\begin{array}{l}\text { 3. Actor's position towards } \\
\text { Objectives }\end{array}$ & $\begin{array}{l}\text { Ranking of objective position and } \\
\text { salience to the actor }\end{array}$ & $\begin{array}{l}\text { Actor } \times \text { Strategic } \\
\text { Issues table }\end{array}$ \\
\hline $\begin{array}{l}\text { 4ctor's Objectives and } \\
\text { Stakes - Means and } \\
\text { Actions }\end{array}$ & $\begin{array}{l}\text { Actions and activities by the actor to } \\
\text { address the objectives }\end{array}$ & Actor $\times$ Actor Table \\
\hline $\begin{array}{l}\text { 5.titudes, Behaviours } \\
\text { and Actions }\end{array}$ & Identifying influence over other actors & Actor $\times$ Actor Table \\
\hline
\end{tabular}

\section{Chart 4: Interview structure to collect the required MACTOR data}

Source: Authors

Real-time interview transcription, such as that used in court reporting, delivers accurate recording of responses and is especially useful when sensitive topics are discussed (Liamputtong, 2011). Such topics have the propensity to create data gathering problems. However, these may be managed by providing respondents with information in advance that explains how respondent confidentiality will be secured and maintained and to develop trust by clearly specifying intentions for research presentation and publication (Ogden, 2008). Even though these measures were undertaken, sensitivity and confidentiality remained a serious issue, with one actor citing this as the reason they declined to participate.

In spite of these concerns there was a reasonably good response rate from actor representatives, $86 \%$ to the initial invitation and a final participation rate of $67 \%$ (34 interviews out of 51 invitations). Even with this response, to ensure balance, the study still required the services of a sector expert to supplement data from one actor. Expert opinion is a data gathering strategy used for MACTOR when complementary data are required (Godet, 1991). While the interviews were audio recorded, the decision was made not to transcribe them due to the data being transformed from in situ into numerical form: reviewing copious written material was deemed to be unnecessary in this case. The recordings remain stored and are available to be reviewed should the actor's contexts, details, motives and contingencies be needed for the later project stages (Godet et al., 2009). Finally, each actor record was given an alphanumeric label, another small but still additional 
contribution towards respondent confidentiality. Chart 5 provides details of the coding used to maintain the participant's confidentiality.

\begin{tabular}{|l|l|l|l|}
\hline Actor & Alpha Short Code & Number of interviews & Code range \\
\hline Consumers & CONSUM & $3^{*}$ & $01-03$ \\
\hline Education Providers & EDPROV & 4 & $01-04$ \\
\hline Government & GOVERN & 3 & $01-03$ \\
\hline Health Providers & HEPROV & 5 & $01-05$ \\
\hline Professional Body & PROBOD & 4 & $01-04$ \\
\hline Regulatory Body & REGBOD & 4 & $01-04$ \\
\hline Representative Body & REPBOD & 11 & $01-11$ \\
\hline Total & - & $\mathbf{3 4}$ & - \\
\hline
\end{tabular}

\section{Chart 5: Actor Code data}

Source: Authors

\subsection{AGGREGATING NUMERICAL DATA}

A data conversion process was developed in this research to meet MACTOR's conventions for assigning numerical values for the two data input tables. The purpose of aggregating the actor's data is to produce a single central data point for each cell in the data entry tables. As the data conventions for MACTOR had been integrated into the data recording form, a set of aggregation conventions was developed to perform this function. In addition to obtaining a central data value for each data set, the aim of the aggregation conventions was to minimise interpretative bias. As the MACTOR software is limited to solely entering integers, the aggregation conventions provide for the rounding of any non-integer rational number produced by the central value calculations to the nearest integer value. Thus, the process is less about precision; rather, it aims to represent the genuine meanings of the respondents' answers as represented in the single aggregated data point.

The interview data were transferred from the data recording forms into tables in an Excel spreadsheet following the relevant MACTOR's coding conventions. The respondent data were then marked into actor group arrays. The number of data points in each data array depend on the number of actors and their responses. Some respondents chose to express an answer over a range of possible values. Therefore, when a respondent suggested a range, the corresponding maximum and minimum code values were entered into the 
data array rather than a single number. This produced some variations in the size of the array data counts. Two sets of aggregation conventions were then applied, each to of the respective data arrays, enabling single central values to be derived (as follows).

\subsubsection{Aggregating Actor X Objective Data}

The first data table requiring aggregation is the Actor $x$ Objective table. To review, this data table contains two types of data: the sign or valence $(+, 0$, or -$)$ and the objective position intensity or salience, which is an integer between 0 and 4 .

To achieve a single value for the data array cells, the numerical position data and the valence or sign data require conventions for aggregation. As the respondents' positions may differ in terms of sign or valence an interpretive method is employed. The aim is to determine the overall valence of the group and as such, majority is used by simple count. If the counts of signs or valences are equal, then the qualitative response data for the array is reviewed and contexts taken into account. This revealed some interesting insights: a number of the respondents when answering questions viewed objectives as positive, but they viewed the process of attaining them to be negative. When interpreting responses the contexts and perspectives are vital to resolve valence conflicts. These nuances and contexts were considered when making adjustments to determine code changes to develop the central value. Should there be no interpretable agreement or contextual indication of change, then the aggregation convention recommended a review of the actor grouping process, as continued disagreement signals a possible need to redefine the actor groups. In this study only 12 cases of sign/valence disagreement were encountered from 224 possible instances. No unresolved sign/valence disagreements were encountered.

The other data in the table are the numerical position or salience data. The central value derivation firstly uses the array cell's median. If the median is not a whole number, then the mode or mean are used to determine its final value. Figure 1 provides the data aggregation conventions as a decision flow 
diagram for both the sign and position variables for the Actor $\mathrm{x}$ Objective data.

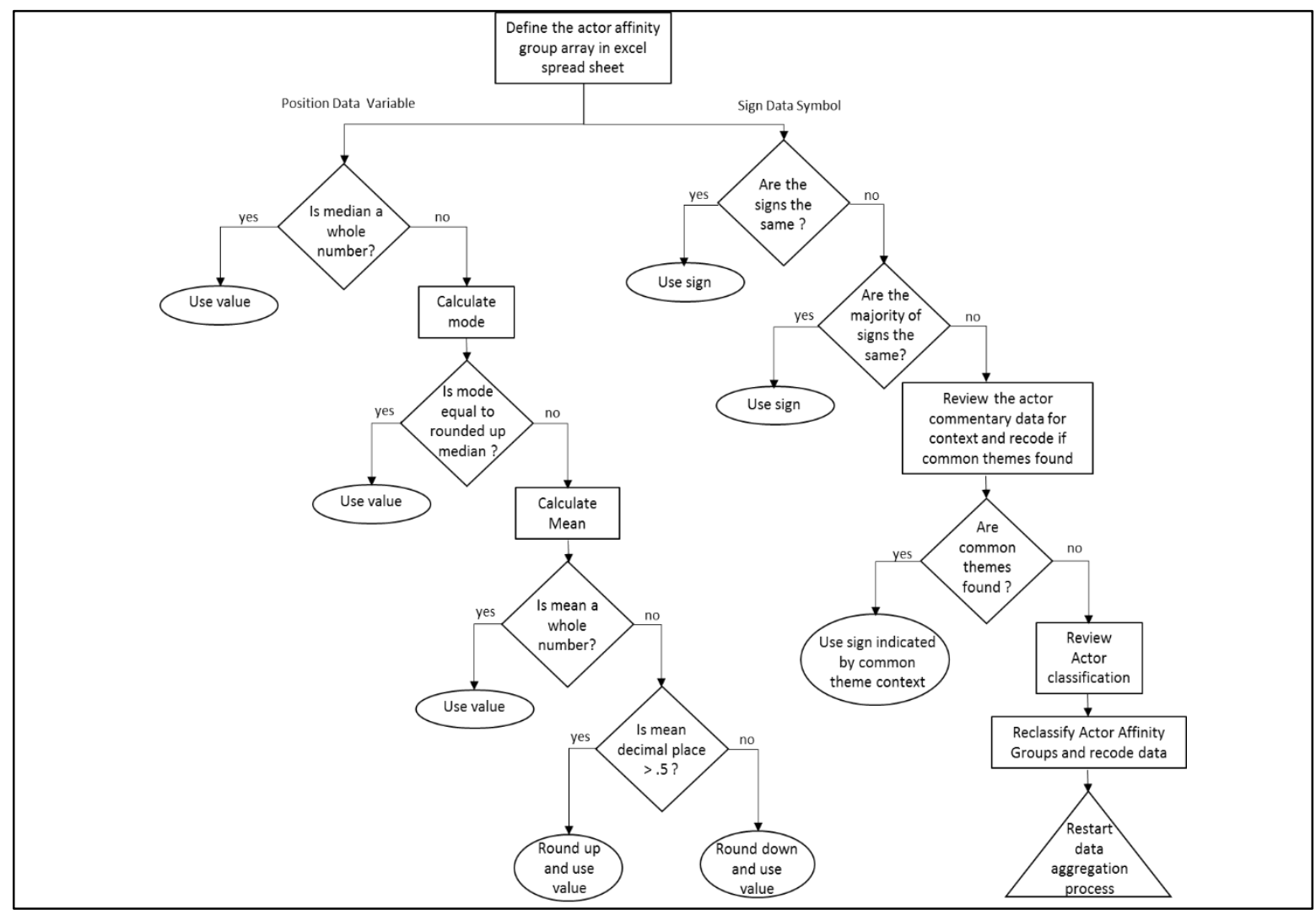

Figure 1: Aggregation Conventions for Actor x Objective data table

Source: Authors

\subsubsection{Aggregating Actor X Actor Data}

The Actor $\mathrm{x}$ Actor table reports each actor's data on their perceived influence over other actors. To review, these data are an integer between 0 and 4.

As with the above aggregation conventions, the numerical central values are derived using descriptive statistics. Following the median's calculation, the criteria for using the mode is detailed. Small data sets are sometimes unable to produce a mode, therefore a threshold for the use of the mode was defined as the $4^{\text {th }}$ quartile range, in the study herein 0 to 8 . Below this threshold, the mean is to be used to determine the central value. Figure 2 provides the data aggregation conventions for the Actor $x$ Actor data entry table as a decision flow diagram. 


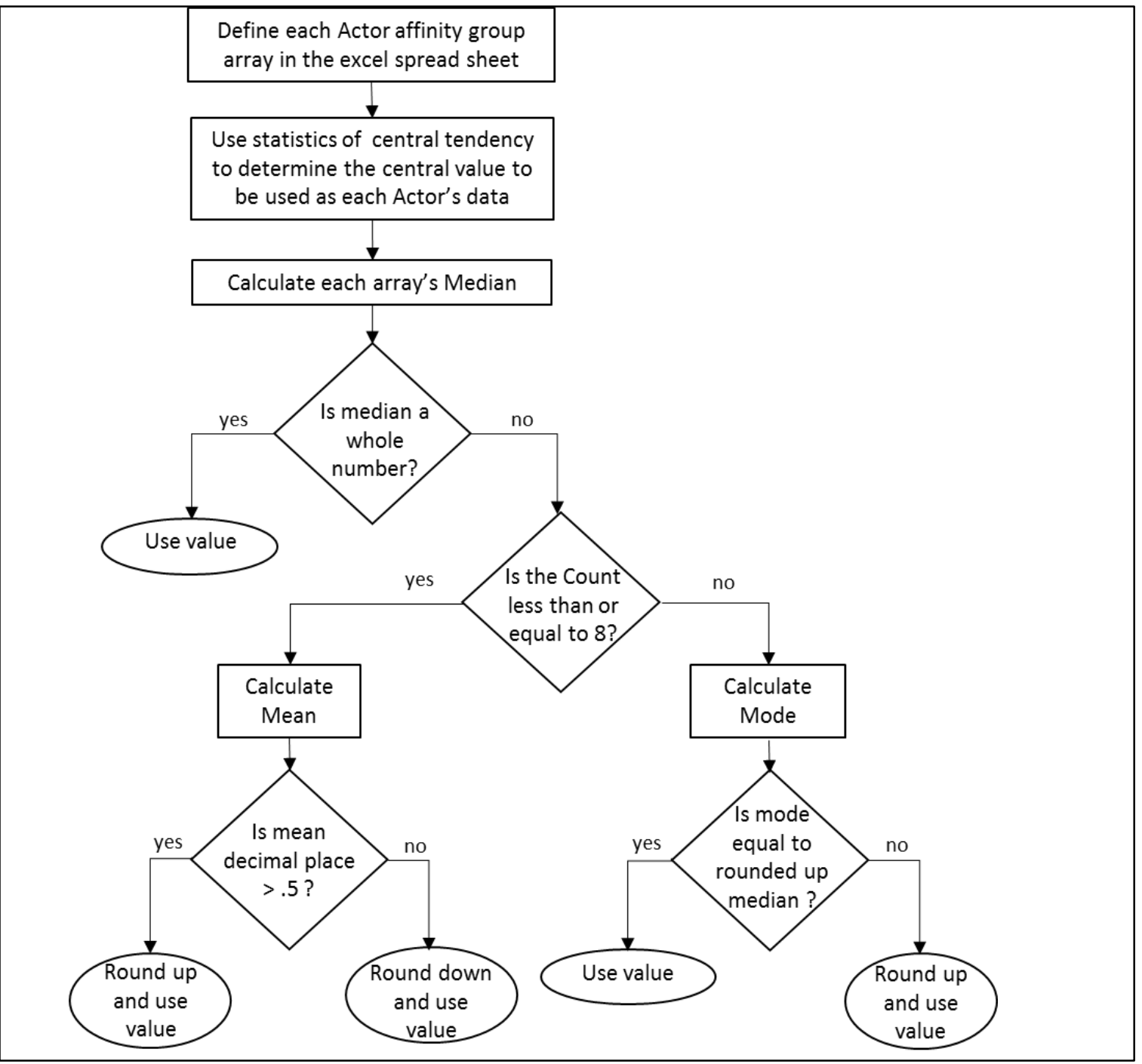

Figure 2: Aggregation Conventions for Actor x Actor data table

Source: Authors

\subsection{THE RESULTING DATA INPUT TABLES}

By applying the aggregation procedures, two sets of data tables were developed for the two different health sub sectors. These tables included the actor's responses that are relevant for that sub sector. Chart 6 presents data on the records used for each sub sector's data tables. The data for sub sector 1 data tables consists of 25 individual actor records, while sub sector two data tables consists of the data from 26 individual actor records. These tables were completed in MS Excel and imported into MACTOR in preparation for data analysis. 


\begin{tabular}{|l|l|l|l|l|}
\hline Actor & Sub Sector 1 & Sub Sector 2 & Both Sub-sectors & Total \\
\hline Consumers & 0 & 0 & 3 & 3 \\
\hline Education Providers & 0 & 1 & 3 & 4 \\
\hline Government & 0 & 1 & 2 & 3 \\
\hline Health Providers & 2 & 2 & 1 & 5 \\
\hline Professional Body & 1 & 2 & 1 & 4 \\
\hline Regulatory Body & 1 & 1 & 2 & 4 \\
\hline Representative Body & 4 & 2 & 5 & 11 \\
\hline Total & $\mathbf{8}$ & $\mathbf{9}$ & $\mathbf{1 7}$ & $\mathbf{3 4}$ \\
\hline
\end{tabular}

\section{Chart 6: Actor data by sub sector}

Source: Authors

\section{A WORKED EXAMPLE OF DATA AGGREGATION}

There follows a worked example of data aggregation provided using samples from the study's data and calculation tables. The first example, using Figure 3, provides sample data and processes used to derive the central values for the Actor $x$ Objective table.

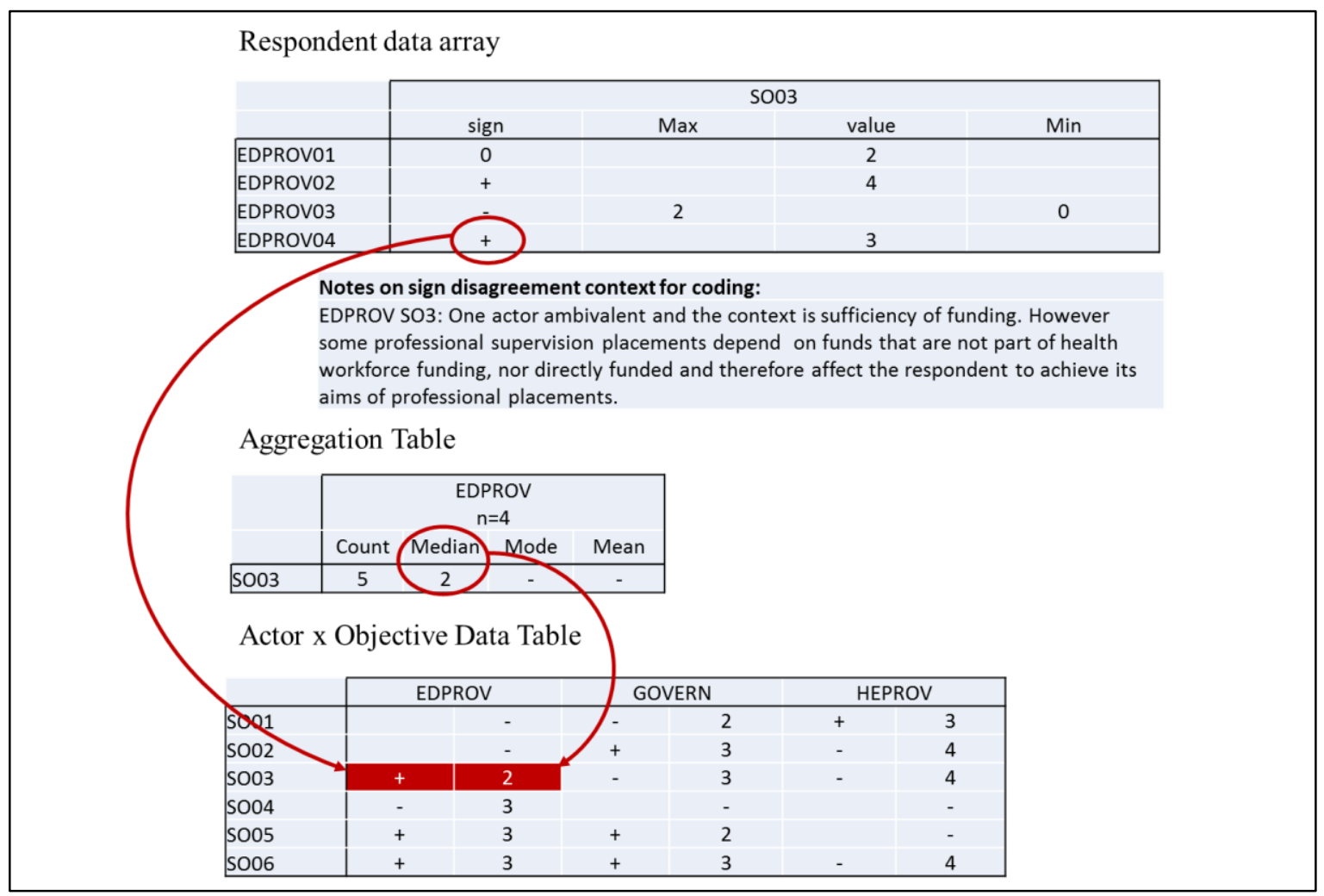

Figure 3: Worked example for the Actor x Objective table

Source: Authors 
The respondent data are entered into the respondent data array, by sign and position saliency numerals. In this example there are four actor respondents (EDPROV01-04) for a single objective (SO03). To derive the sign or valence value from the array the sign data are counted and the majority sign is selected. In the example there is a neutral value, so the contexts of responses were reviewed to ensure the sign fairly represented the respondent's views. This example's context is reviewed with EDPROV03 response retained as a negative position. Review of the contexts and response data support the sign derivation and may involve making a value judgement on the choice of array sign or valence.

Next, the position or salience value is derived following that part of the aggregation convention. The array count in this example is 5 , with a median of 2. If the array median is a whole number this this is used for the salience value (as per Figure 1). The result of this example entered into the Actor $x$ Objective data table is +2 .

The second example, using Figure 4, provides sample data and processes used to derive the central values for the Actor $x$ Actor table.

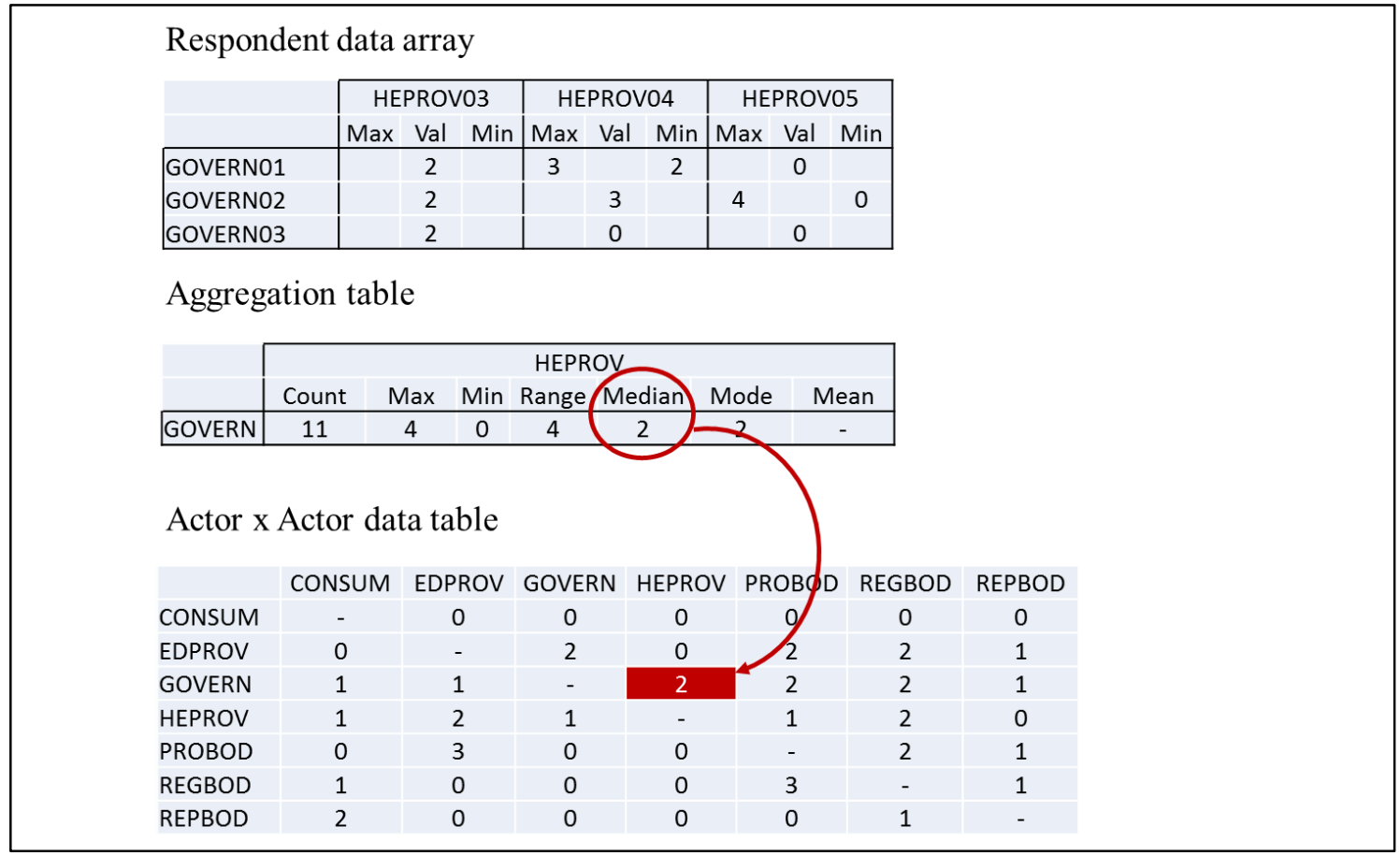

Figure 4: Worked example for Actor x Actor table data.

Source: Authors 
As in the prior example all respondent data are entered into an Excel sheet and the appropriate array boundaries are set. The data array's descriptive statistics are used to derive the central value used in the data table.

For this example the array is made up of three respondents for the actor group HEPROV and three for the actor group GOVERN. The array maximum and minimum values are used to calculate the array range, while the median and mode are also calculated. The median is a whole number and as the array count is 11 , greater than the quartile threshold, calculating the mean is not necessary. Following the aggregation convention (Figure 2), the median is selected as the array central value and entered into the Actor $\mathrm{x}$ Actor table for entry into the MACTOR software.

\section{FINAL CONSIDERATIONS}

In this research note the aim was to introduce a novel method to attain quality actor analysis data for use in a foresight project. Actor's data are sometimes difficult to secure, requiring new approaches to be devised. Further, actor's data may suffer from heightened sensitivity, which requires a number of measures to be taken by the researcher to ensure responden'st recruitment, engagement and trust.

The process that has been described hereinoffers a systematic way of gathering disparate data from a number of interviews and aggregating themto derive a single central data point to use in the MACTOR's actor's analysis tool. The tool has data entry limitations requiring the aggregated data to meet certain specifications. These specifications informed the data gathering design and aggregation conventions. While the method described the nature of aggregation its derivation processes may mask data subtleties and nuances from each actor. To address this, context reviews are undertaken as the process proceeds, further utilising the rich data that the interviews provide. While the process retains the existing weakness of the MACTOR as described by Bendahan et al. (2004), it goes indeed some way to contribute to result quality through its focus on the quality of the input data. 
As the focus of this article is to present a new methodological approach to actor's data collection and coding for MACTOR, wider results from its application have not been presented. However, two methodological benefits can be identified. Firstly, collecting data from individual respondents rather than from a group or experts provides additional flexibility for data management. In this case the actors' responses were a group based on the industry structure. However, the actors could have just as easily been arranged in a different configuration, directed by the analysis framework being used. For instance, the actors may be arranged by profession. This actor configuration could then be used as part of a process to better understand the effects of medical inter-professional rivalry concerning the industry strategic objectives and strategizing for change. The data collection and aggregation procedures developed and presented above are neutral to the actor's categorisation process. Secondly, the process provides consistency for the data collection from a large number of respondents. By following the same procedures for each interview and using explicit criteria for data organization and classification, research biases are reduced (Varvasovszky \& Brugha, 2000). This means that the aggregated data can be better relied upon to present a reasonable central position for an actor group, while each group's individual data can be revisited to understand how a strategic or contentious issue may affect a particular organization.

This method feature contributed to the results analysis. When examining the i actor power's nfluence over a particular strategic issue, the actor's data as a whole as well as the individual records are able to be reviewed. This has the potential to cast a more nuanced view of the effects on or by actors and reveal the importance of the implications of a particular issue across the actor groups. This type of analysis would be more difficult when using single-point data collected from workshops or from the opinions of a single or group of experts.

To close, when introducing MACTOR, Godet (1991) believed that it would disseminate rapidly due to its simplicity and utility to understand actor's games and power relationships. The peer reviewed literature, however, suggests otherwise. There are few published studies describing MACTOR in detail and/or any application and method improvements. It has 
been proposed that the actor's ata sensitive nature may have prevented the publication of more studies using MACTOR and from revealing the potential and applied improvements to the method. However, judging by the reported number of software downloads it is more likely that the method is used more frequently than the academic literature tends to indicate (Coates, 2006).

\section{ACKNOWLEDGEMENTS}

The authors would like to thank the paper's reviewers for thoughtful comments, to Professors Robin Gauld and Peter Crampton for their support throughout the project and to the extremely busy leadership, staff and stakeholders of New Zealand's health workforce system. 


\section{REFERENCES}

Ahmed, M. T., Saleh, M., Abdelkadir, A. F., \& Abdelrehim, A. (2009). El Maghara scenario a search for sustainability and equity: An Egyptian case study. Journal of Futures Studies, 14(2), 55-90.

Arcade, J., Godet, M., Meunier, F., \& Roubelat, F. (2009). Structural analysis with the MICMAC method \& actor's strategy with MACTOR method. In J. C. Glenn \& T. J. Gordon (Eds.), Futures Research Methodology - V3.0 (pp. 1-69). Washington, DC: The Millennium Project. Retrieved from http://www.millennium-project.org/millennium/FRM-V3.html.

Bendahan, S., Camponovo, G., \& Pigneur, Y. (2004). Multi-issue actor analysis: tools and models for assessing technology environments. Journal of Decision Systems, 13(2), 223-253.

Bettencourt, R. (2010). Strategic prospective for the implementation of employment policies in the Azores. Technological Forecasting and Social Change, 77(9), 1566-1574. doi: 10.1016/j.techfore.2010.06.026

Bijl, R. (1992). Delphi in a future scenario study on mental health and mental health care. Futures, 24(3), 232-250. doi: 10.1016/00163287(92)90033-C

Cairns, G., Wright, G., \& Fairbrother, P. (2016). Promoting articulated action from diverse stakeholders in response to public policy scenarios: A case analysis of the use of 'scenario improvisation' method. Technological Forecasting and Social Change, 103, 97-108. doi: 10.1016/j.techfore.2015.10.009

Cicourel, A. V. (1964). Method and measurement in sociology. New York: The Free Press.

Coates, J. F. (2006). Preface. In M. Godet (Ed.), Creating futures: Scenario planning as a strategic management tool (2 ed., pp. XI). Paris: Economica Ltd.

de Savigny, D., \& Adam, T. (2009). Systems thinking for health systems strengthening. Geneva: World Health Organisation. 
Garrett, M. J. (1999). Health futures: a handbook for health professionals. Geneva: World Health Organisation.

Gauld, R. (2005). New Zealand. In R. Gauld (Ed.), Comparative health policy in the Pacific (pp. 200-224). Maidenhead: Open University Press.

Glouberman, S., \& Mintzberg, H. (2001). Managing the care of health and the cure of disease-Part I: Differentiation. Health Care Management Review, 26(1), 56-69.

Godet, M. (1979). The crisis in forecasting and the emergence of the "prospective" approach: with case studies in energy and air transport Pergamon Policy Studies (Vol. 15). Oxford: Pergamon Press.

Godet, M. (1982). From Forecasting to 'La Prospective' A New Way of Looking at Futures. Journal of Forecasting, 1(3), 293-301.

Godet, M. (1991). Actors' moves and strategies: The mactor method. An air transport case study. Futures, 23(6), 605-622.

Godet, M. (2000). The art of scenarios and strategic planning: Tools and pitfalls. Technological Forecasting and Social Change, 65(1), 3-22. doi: $10.1016 / s 0040-1625(99) 00120-1$

Godet, M. (2006). Creating futures: Scenario planning as a strategic management tool ( 2 ed.). Paris: Economica Ltd.

Godet, M., Bassaler, N., Monti, R., \& Richou, S. (2004). LIPSOR's Guideline for strategic prospective workshops. Paris: LIPSOR.

Godet, M., Monti, R., Meunier, F., \& Roubelat, F. (2009). A tool box for scenario planning. In J. C. Glenn \& T. J. Gordon (Eds.), Futures Research Methodology - V3.0 (pp. 1-73). Washington, DC: The Millennium Project. Retrieved from http://www.millenniumproject.org/millennium/FRM-V3.html.

Gorman, D. F. (2015). Developing health care workforces for uncertain futures. Academic Medicine, 90(4), 400-403. doi: 10.1097/ACM.0000000000000644 
Gorman, D. F., \& Brooks, P. M. (2009). On solutions to the shortage of doctors in Australia and New Zealand. Medical Journal of Australia, 190(3), 152-156.

Health Workforce Advisory Committee. (2005). Fit for purpose and practice: a review of the medical workforce in New Zealand (pp. 1-168). Wellington: Health Workforce Advisory Committee.

Heger, T., \& Rohrbeck, R. (2012). Strategic foresight for collaborative exploration of new business fields. Technological Forecasting and Social Change, 79(5), 819-831. doi: 10.1016/j.techfore.2011.11.003

Hinings, C. R. (2004). Professions in organizations. In N. J. Smelser \& P. B. Baltes (Eds.), International encyclopedia of the social and behavioral sciences (pp. 12160-12166). Amsterdam: Elsevier.

Lafourcade, B., \& Chapuy, P. (2000). Scenarios and Actors' Strategies: The Case of the Agri-Foodstuff Sector. Technological Forecasting and Social Change, 65(1), 67-80. doi: 10.1016/S0040-1625(99)00128-6

Lakner, Z. (2013). Main actors and their strategies in Hungarian higher education. Acta Oeconomica, 63(2), 201-224. doi: 10.1556/AOecon.63.2013.2.4

Liamputtong, P. (2011). Focus group methodology: Principle and practice. London: Sage Publications.

Lo, C.-C., Wang, C.-H., \& Huang, C.-C. (2013). The national innovation system in the Taiwanese photovoltaic industry: A multiple stakeholder perspective. Technological Forecasting and Social Change, 80(5), 893906. doi: 10.1016/j.techfore.2012.08.016

MacKay, R. B., \& McKiernan, P. (2010). Creativity and dysfunction in strategic processes: The case of scenario planning. Futures, 42(4), 271-281. doi: $10.1016 /$ j.futures.2009.11.013

Masini, E. B., \& Medina Vasquez, J. (2000). Scenarios as seen from a human and social perspective. Technological Forecasting and Social Change, 65(1), 49-66. doi: 10.1016/S0040-1625(99)00127-4 
Munteanu, R., \& Apetroae, M. (2007). Journal relatedness: An actor-actor and actor-objectives case study. Scientometrics, 73(2), 215-230. doi: $10.1007 / \mathrm{s} 11192-007-1735-7$

National Health Workforce Planning and Research Collaboration. (2011). Alternative approaches to health workforce planning: Final report ( $p p$. 1-56). Adelaide: Health Workforce Australia.

Ogden, R. (2008). Sensitive topics. In L. M. Given (Ed.), The Sage Encyclopedia of Qualitative Research Methods (pp. 811-812). Thousand Oaks, CA: Sage Publications.

Pincombe, B., Blunden, S., Pincombe, A., \& Dexter, P. (2013). Ascertaining a hierarchy of dimensions from time-poor experts: Linking tactical vignettes to strategic scenarios. Technological Forecasting \& Social Change, 80(4), 584-598. doi: 10.1016/j.techfore.2012.05.001

Riedy, C. (2009). The influence of futures work on public policy and sustainability. Foresight, 11(5), 40-56. doi: $10.1108 / 14636680910994950$

Taylor, M. C. (2005). Interviewing. In I. Holloway (Ed.), Qualitative Research in Health Care. Maidenhead, Berkshire: McGraw-Hill International.

Varvasovszky, Z., \& Brugha, R. (2000). A stakeholder analysis. Health Policy and Planning, 15(3), 338-345.

Vivanco-Aranda, M., Mojica, F. J., \& Martínez-Cordero, F. J. (2011). Foresight analysis of tilapia supply chains (Sistema Producto) in four states in Mexico: Scenarios and strategies for 2018. Technological Forecasting and Social Change, 78(3), 481-497. doi: 10.1016/j.techfore.2010.05.005

Wright, G., \& Cairns, G. (2011). Scenario thinking: Practical approaches to the future. Basingstoke, UK: Palgrave Macmillan.

Wright, G., \& Goodwin, P. (2009). Decision making and planning under low levels of predictability: Enhancing the scenario method. International Journal of Forecasting, 25, 813-825. doi: 10.1016/j.ijforecast.2009.05.019 
Yamakawa, P., Cadillo, G., \& Tornero, R. (2012). Critical factors for the expansion of broadband in developing countries: The case of Peru. Telecommunications Policy, 36(7), 560-570. doi: 10.1016/j.telpol.2012.03.004 